\title{
Preliminary Design of the ITER ECH Upper Launcher
}

\author{
D. Strauss ${ }^{1}$, G. Aiello ${ }^{1}$, R. Chavan ${ }^{2}$, S. Cirant ${ }^{3}$, M. deBaar ${ }^{4}$, D. Farina ${ }^{3}$, G. Gantenbein ${ }^{1}$, T. P. Goodman ${ }^{2}$, M.A. \\ Henderson $^{8}$, W. Kasparek ${ }^{6}$, K. Kleefeldt ${ }^{1}$, J.-D. Landis ${ }^{2}$, A. Meier ${ }^{1}$, A. Moro ${ }^{3}$, P. Platania ${ }^{3}$, B. Plaum ${ }^{6}$, E. Poli ${ }^{5}$, G. \\ Ramponi $^{3}$, D. Ronden ${ }^{4}$, G. Saibene ${ }^{7}$, F. Sanchez ${ }^{2}$, O. Sauter ${ }^{2}$, T. Scherer ${ }^{1}$, S. Schreck ${ }^{1}$, A. Serikov ${ }^{1}$, C. Sozzi ${ }^{3}$, P. \\ Spaeh $^{1}$, A. Vaccaro ${ }^{1}$, H. Zohm ${ }^{5}$ \\ ${ }^{1}$ Karlsruhe Institute of Technology, Assoc. KIT-EURATOM, D-76021 Karlsruhe, Germany \\ ${ }^{2}$ Centre de Recherches en Physique des Plasmas, CRPP-EPFL, CH-1015 Lausanne, Switzerland \\ ${ }^{3}$ Istituto di Fisica del Plasma CNR, Euratom Association, 20125 Milano, Italy \\ ${ }^{4}$ FOM, Van Vollenhovenlaan 659, 3527 JP, Utrecht, Netherlands \\ ${ }^{5}$ Max-Planck-IPP, Euratom Association, D-85748 Garching, Germany \\ ${ }^{6}$ Institut für Plasmaforschung, IPF, D-70569 Stuttgart, Germany \\ ${ }^{7}$ Fusion for Energy, Barcelona, Spain \\ ${ }^{8}$ ITER Organization, 13108 Saint-Paul-lez-Durance, France
}

\begin{abstract}
The design of the ITER electron cyclotron launchers recently reached the preliminary design level - the last major milestone before design finalization. The ITER ECH system contains 24 installed gyrotrons providing a maximum ECH injected power of $20 \mathrm{MW}$ through transmission lines towards the tokamak. There are two EC launcher types both using a front steering mirror; one equatorial launcher (EL) for plasma heating and four upper launchers (UL) for plasma mode stabilization (neoclassical tearing modes and the sawtooth instability). A wide steering angle range of the ULs allows focusing of the beam on magnetic islands which are expected on the rational magnetic flux surfaces $q=1$ (sawtooth instability), $q=3 / 2$ and $q=2$ (NTMs).
\end{abstract}

In this paper the preliminary design of the ITER ECH UL is presented, including the optical system and the structural components. Highlights of the design include the torus CVDdiamond windows, the frictionless, front steering mechanism and the plasma facing blanket shield module (BSM). Numerical simulations as well as prototype tests are used to verify the design

Keywords: ITER; Electron cyclotron heating; mm-wave optics; diamond windows; prototyping; testing

\section{INTRODUCTION}

The next generation international fusion reactor ITER is designed to reach 500MW of fusion power with pulse durations of several minutes. A power amplification of 10 under stationary conditions is targeted (ratio between the fusion power and the required heating power, see table 1). Three plasma heating systems are foreseen: Neutral Beam Injection, Ion Cyclotron Heating and the Electron Cyclotron Heating (ECH, see figure 1). Of these heating systems ECH has the best capability of providing the necessary plasma mode stabilization in the tokamak allowing long pulse operation.
Table 1: Nominal ITER parameters.

\begin{tabular}{|c|c|}
\hline Major plasma radius & $6.2 \mathrm{~m}$ \\
\hline Minor plasma radius & $2 \mathrm{~m}$ \\
\hline Plasma volume & $840 \mathrm{~m}^{3}$ \\
\hline Plasma current & $15 \mathrm{MA}$ \\
\hline Toroidal field on axis & $5.3 \mathrm{~T}$ \\
\hline Fusion power & $500 \mathrm{MW}$ \\
\hline Pulse length & $>400 \mathrm{~s}$ \\
\hline Power amplification & $>10$ \\
\hline
\end{tabular}

The power of $24 \mathrm{MW} \mathrm{ECH}$ at $170 \mathrm{GHz}$ is foreseen to be provided by three domestic agencies [1]; 8 gyrotrons of 1MW each are developed in Japan [2], 8 gyrotrons of 1MW by the Russian Federation [3] and 4 gyrotrons of 2MW power by the European Union [4]. A large set of transmission lines [5] connects the gyrotrons to a smaller set of launchers which inject the mm-wave power into the plasma. One equatorial launcher (24 lines, [6]) serves for central plasma heating with a limited current profile shaping ability while four upper launchers (8 lines each, see figure 2) drive current locally for mode stabilization. As the ECH is based on a fixed frequency, a steerable mm-wave beam allows a continuous range of angles to aim at the various resonant flux surfaces. When an instability is observed, the ECH Upper Launcher system has to be steered to the required location, in a limited time, to maintain control of the plasma. The main purpose of the UL is to stabilize the neoclassical tearing modes (NTMs, [7]) and to control the sawtooth instability [8]. The most important magnetic flux surfaces for the NTMs are $q=2 / 1$ and $3 / 2$, whereas for control of the sawtooth instability the steering range [9] must also cover the $\mathrm{q}=1$ region.
This work was supported by EFDA under the contract TW6 and Fusion for Energy under the contract No. F4E-2009-OPE-051. The views and opinions expressed herein reflect only the author's views. EFDA and Fusion for Energy are not liable for any use that may be made of the information contained therein. 


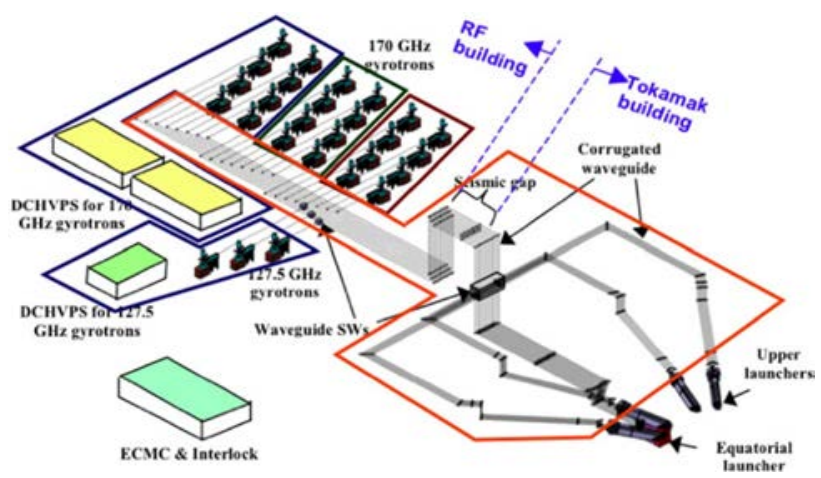

Figure 1. ITER ECH system [10]

The main challenges for ITER plasma facing components such as the ECH launchers arise from the extreme operating conditions; e.g. heat loads, neutron flux or possible plasma disruptions causing severe mechanical loads. In addition, the ECH launchers must provide appropriate beam steerability and focusing, while handling the high power mm-wave beams and the associated heat loads on the windows and mirrors. The most sophisticated components are the diamond window units made up by artificially grown CVD-diamond disks brazed to window housings, the friction free front steering mechanism and the first wall panel with its plasma facing surface.

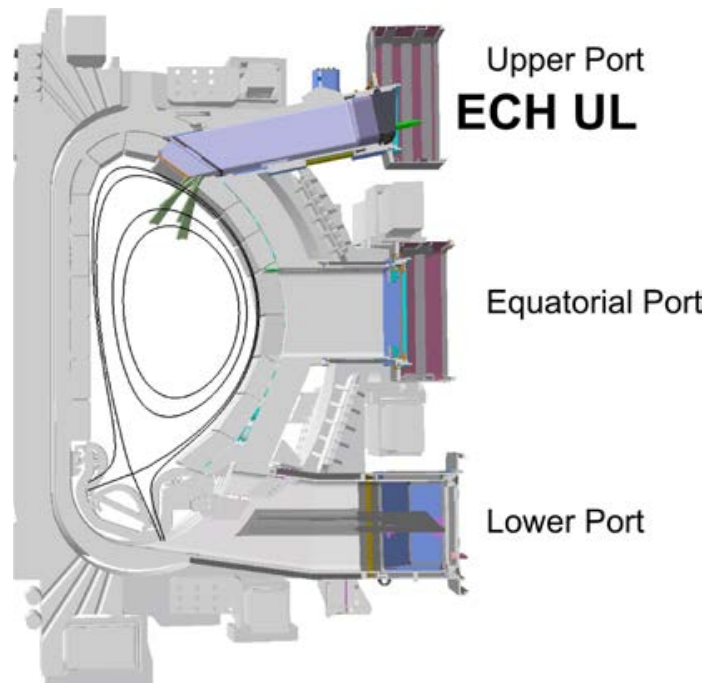

Figure 2. Torus segment with the ECH Upper Launcher.

\section{DESIGN OF THE ECH UPPER LAUNCHER}

\section{A. Overview}

The upper launcher shown in figure 3 will be mounted in 4 of the 18 upper port plugs in ITER with the use of a flange at the rear side on launcher socket. It has an overall length of $6 \mathrm{~m}$, a height of $1.1 \mathrm{~m}$ and a width of the trapezoidal mainframe of $0.52 \mathrm{~m}$ on the top and $0.87 \mathrm{~m}$ on the lower cross section with a dead weight of 16t. The upper launcher design includes the launcher itself, ten cooling lines as well as four pressurized He lines used for the steering mirrors, eight waveguides and ends at the diamond windows, which form the confinement barrier towards transmission lines and the gyrotrons. The mainframe is designed for maximum stiffness against Lorenz forces during disruptions [11] with a thick single wall on the rear side, but an actively cooled double wall structure on the front side ending with a flange to the plasma facing blanket shield module. The millimeter wave beams pass through the ultra-low-loss diamond windows, then waveguides, to a quasi-optical system inside the launcher. A dogleg beam path - formed by several mirrors - through the back and internal shield blocks avoids line-of-sight neutron streaming [12]. The beams are focused to the front steering mirrors and reflected to the target location in the plasma.

\section{B. The millimeter-wave system}

The UL design is a front steering system (FS) with two independently moveable steering mirrors; the upper and lower steering mirrors (USM, LSM) close to the first wall. They offer a wide angular steering range sufficient to cover the required range for NTMs and the sawtooth instability. Based on the conceptual upper launcher design [13] the analysis of different optical beam paths [14] led to a modification of the optical design from a mitre bend solution towards a quasi-optical system, increasing the steering range and thereby the upper launcher performance. With the new "Extended Physics Launcher" (EPL, [15]) the steering angles of USM and LSM have been decoupled, the goal is to cover a range between $\rho_{\mathrm{T}}=0.3$ to near the plasma edge at $\rho_{\mathrm{T}}=0.95$. With an overlap in the NTM regime; the extended range allows (in addition to NTM and sawtooth stabilization) triggering in the Frequency Interrupted Regime (FIR) and opens the possibility of Edge Localized Modes (ELMs) control. The EPL now also contributes to co-ECCD on the $\mathrm{q}=1$ surface relieving the coECCD requirements for the EL. This opens, for the EL design, the possibility to use one out of three beam rows for counter ECCD thereby providing additional capabilities on $\mathrm{j}_{\mathrm{p}}$ tailoring. The UL mm-wave system consists of two rows with 4 transmission lines, the maximum power per row is $1.8 \mathrm{MW}$. CVD diamond torus-window units form the first tritium barrier to the torus; in case of a failure, isolation valves on each beam line can be closed. Continued operation with the remaining beam lines is therefore possible, which is beneficial for ITER uptime in the case of a window failure. After two rows of mitre bends the waveguides pass through the closure plate in the UL back end. In the subsequent dogleg-shaped optical path the beams hit two mirror sets placed in the middle of the launcher and propagate toward the blanket shield module (BSM) through an internal shield block. A focusing mirror reflects the beams toward the actively steered mirrors units USM/LSM, the overlapping beams passes the cut out in the first wall and interacts with the plasma. 


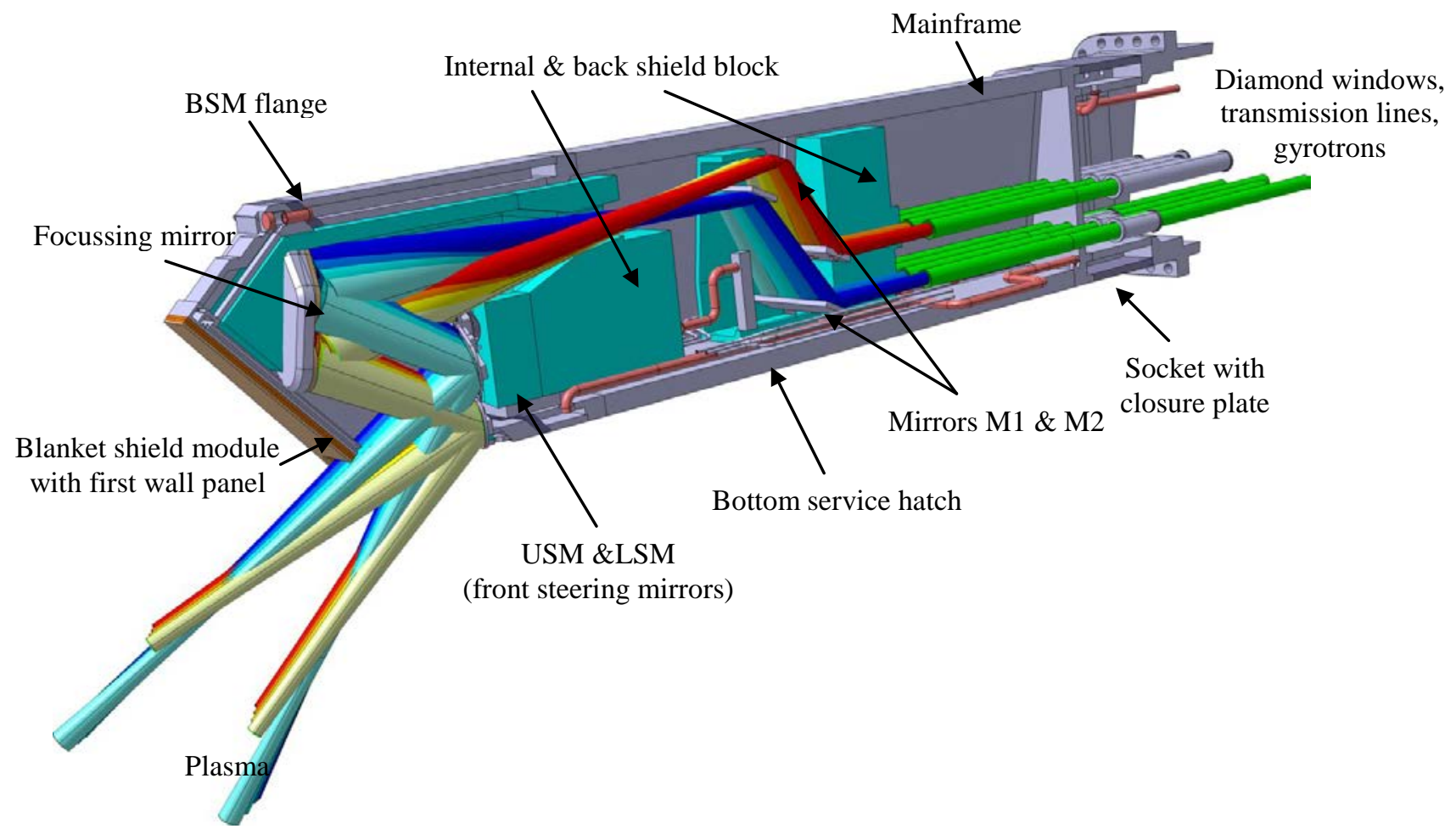

Figure 3. Schematic view on the ITER ECH Upper Launcher.

\section{Design validation}

The design of the upper launcher uses analytical calculations, simulations and prototype testing, to ensure compliance with the design requirements and the availability of suitable manufacturing routes. The simulations incorporate neutron analyses including component activation and $\mathrm{He}$ formation, thermo-mechanical analyses, fluid dynamics and electro-magnetic simulations of plasma disruptions. With the latter it could be shown that, during worst case disruptions (upward fast VDE with a linear decay of 15MA within 36ms), significant deflection occurs and that the ITER requirement of a $10 \mathrm{~mm}$ gap between neighboring components dictated a design close to the limit of being physically possible. The induced currents act by Lorenz forces with torque moments above the $1 \mathrm{MN}$ range on the port plug and the port itself; this leveraged system has an overall length of roughly $10 \mathrm{~m}$, which is very high compared to the $10 \mathrm{~mm}$ requirement. As a result, the allowed gap for deflections was increased by ITER to $13 \mathrm{~mm}$. This new requirement is fulfilled by the preliminary design ([11], [16]).

Prototyping of the most critical components has been initiated. Different manufacturing routes have been evaluated to compare the possibilities of realizing actively cooled structural components using hot isostatic pressing, brazing, welding and gun drilling. A diamond window prototype has been manufactured and tested at low and high power. On another front, the lifetime of bellows for the steering mirror mechanism was evaluated.
For testing huge structural components a prototype test facility, the Launcher Handling Test facility LHT, has been constructed. The most critical component to be tested is the blanket shield module BSM.

\section{DESCRIPTION OF SELECTED KEY LAUNCHER SUBSYSTEMS}

\section{A. Diamond windows}

With the increasing capabilities of gyrotrons the development of artificial CVD diamond disks opened the path to the state of the art high power mm-wave transmission windows. The ITER ECH system is fixed to a frequency of $170 \mathrm{GHz}$; the diamond window thickness is $1.11 \mathrm{~mm}$. A critical issue of the disk growth and the following surface treatment is the avoidance of sp2 carbon on grain boundaries and the surfaces for reduced transmission losses and therefore heat generation in the disk.

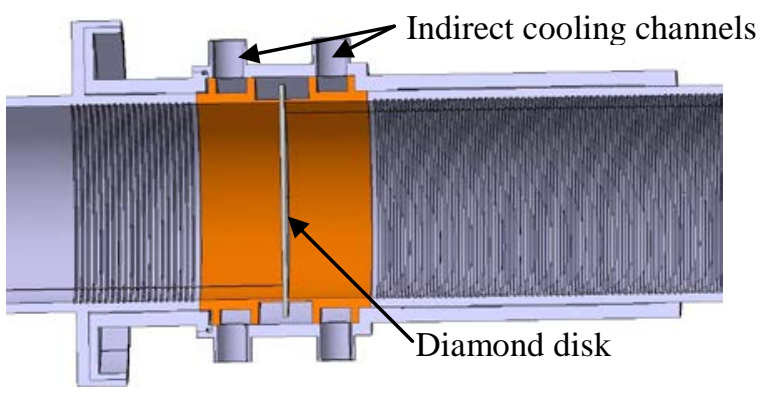

Figure 4. The ITER ECH Torus Diamond Window. 
For the ITER torus window [17] the transmission losses are low enough ( $\sim 200 \mathrm{~W}$ in a $2 \mathrm{MW}$ beam for a state of the art disk with $\tan \delta=10^{-5}$ ) to allow an indirect cooling of the disk without direct contact between the cooling water and the diamond (figure 4). A major benefit is the tritium barrier between the disk and the coolant in the unfortunate case of a window failure.

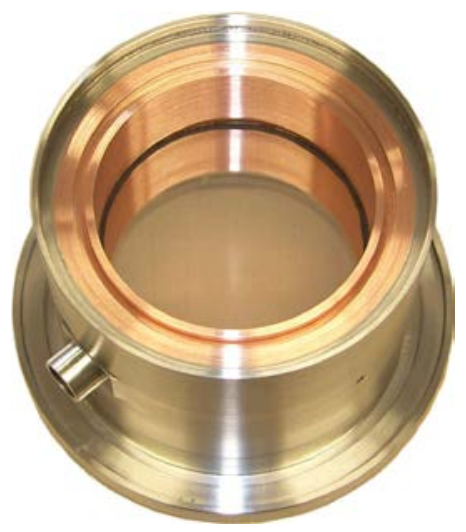

Figure 5. Torus diamond window prototype.

The disks are brazed to $\mathrm{Cu}$-cuffs by a reactive Ag-Cu braze containing $\mathrm{Ti}$, which provides an excellent bonding between the covalent diamond and the metallic cuffs. Compared to diffusion based joining (e.g. Al in combination with Inconel cuffs) relatively low brazing temperatures around $850^{\circ} \mathrm{C}$ are required. With a thermal expansion coefficient of diamond being a factor 19 lower than that of $\mathrm{Cu}$, the low brazing temperatures are beneficial in terms of stress generation. The window assembly is completed with the integration into the steel housing with double HELICOFLEX ${ }^{\circledR}$ connections to the waveguides.
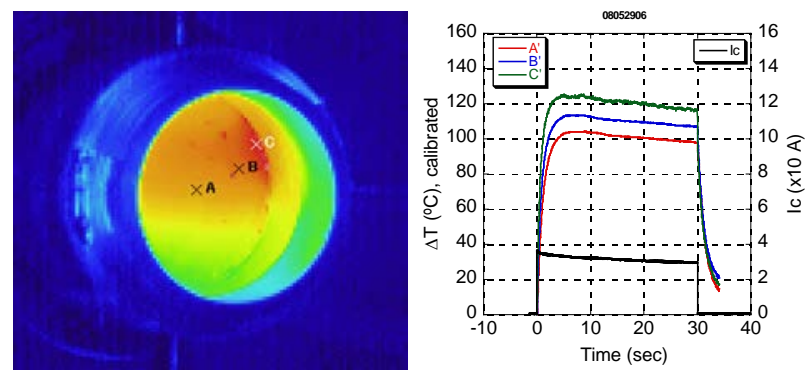

Figure 6. High power torus window test performed at JAEA, 520kW.

A torus window prototype (figure 5) was manufactured and tested at JAEA in a transmission line connected to an ITER prototype gyrotron operating at $170 \mathrm{GHz}$. As the diamond window was operated on one side in air for IR measurements the maximum beam power had to be limited to $520 \mathrm{~kW}$ to avoid arcing and a possible diamond disk failure (figure 6). Higher order modes coupled into a small gap in the diamond window assembly causing unwanted local heating. As a result ITER now requires a high mode purity to avoid local heating not only in the diamond window unit, but also in the shutter valve and the quasi-optical section in the launchers. As these mode impurities could lead to failures of the costly diamond window units a design upgrade has been introduced in which the inner section of the window unit is filled with a corrugated waveguide covering the gaps in the assembly [18].

\section{B. Front steering mechansim}

The cantilevered front steering mirrors (figure 7) consist of the mirror, rotor and stator, the supply lines for cooling and He for angular steering [15]. The mirror rotates around a frictionless flexure pivot driven by He-pressurized bellows and counteracting springs.

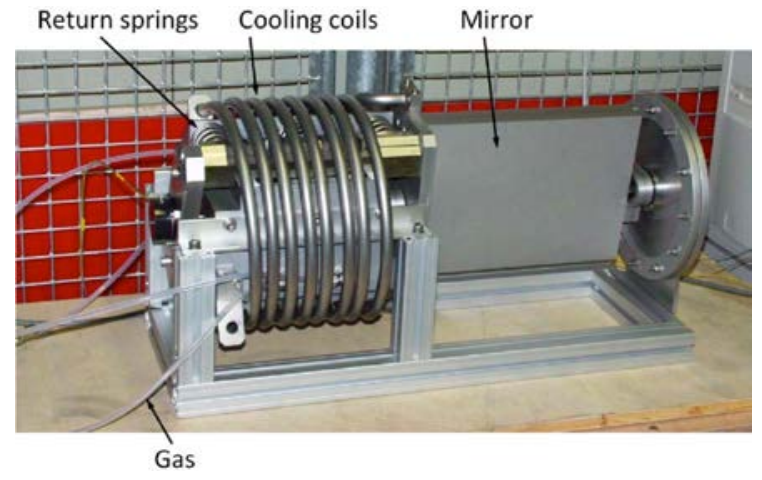

Figure 7. First front steering mirror prototype at CRPP.

For ITER lifetime up to 30000 steering cycles for NTM stabilization are foreseen. This implies cyclic fatigue especially in the bellows, which have to withstand He pressures up to $2 \mathrm{MPa}$ as well as the angular cycling of $\pm 7^{\circ}$ with a steering speed of $2 \mathrm{~s}$ for a full period. To fulfill the high mechanical requirements a $\mathrm{Ni}$ base superalloy has been chosen; these alloys are well known for their use for aviation turbine blades in combination with an MCrAlY-type oxidation resistant bond coat and ceramic thermal barrier coatings [19]. The selected IN718 is Ni based with $\mathrm{Cr}$ as the second element and, among others, $\mathrm{Nb}$ for the formation of $\gamma^{\prime}-\mathrm{Ni}_{3} \mathrm{Nb}$ precipitations. In common Ni- or Fe-based austenites dislocations can propagate easily and accumulate initiating microcracks; the role of the $\gamma^{\text {' }}$ precipitates is to pin dislocations homogeneously distributed over the alloy leading to an outstanding cyclic fatigue and creep behaviour. Due to the lack of a high neutron flux materials testing facility it is difficult to predict the long term stability of the $\gamma$ ' precipitates; therefore cyclic fatigue testing of bellows made by IN718 as well as by pure Ni (as a material with "worst case" properties due to lost $\gamma$ ') were performed to check compliance with the cyclic fatigue requirements.

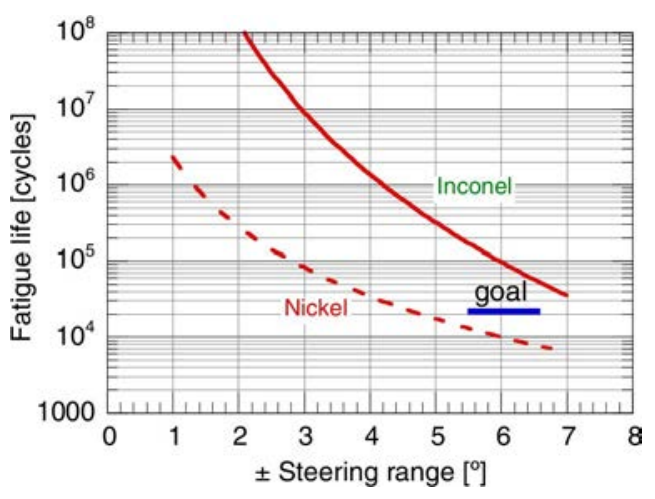

Figure 8. Fatigue test of $\mathrm{Ni}$ and In718 bellows. 
The experiments summarized in figure 8 show the high lifetime for bellows made of IN718. For a smaller steering range below $\pm 5^{\circ} \mathrm{Ni}$ also fulfills the cycle criteria, in practice the usual steering will not extend to the full $\pm 7^{\circ}$.

\section{The blanket shield module}

In contrast to the diagnostic upper port plug development the upper launcher design includes the plasma facing BSM (figure 9); bolted to the main structure by a flange. Due to the high heat and neutron loads in combination with mm-wave stray radiation a double wall housing design was developed for homogeneous cooling by rectangular channels in the side walls. The first wall panel consists of a steel plate with parallel stainless steel cooling tubes embedded in a heat sink made of CuCrZr; this structure is covered by a $1 \mathrm{~cm}$ thick Be layer on the plasma facing side. The blanket shield module houses the focusing and the front steering mirrors and further contains shielding elements for neutron protection of weldings and the toroidal field coils. The design requires a sophisticated powder metallurgical manufacturing route using hot isostatic pressing (HIP). In the first step the steel housing is formed. After that the $\mathrm{CuCrZr}$ embedded parallel cooling tubes are joined to the first wall panel by a second HIP step. An extra challenge is the last HIP step, where the Be layer is added. The difficulty is, that during this step the Be powder requires a temperature above the one recommended for CuCrZr. The heat ramp during the last HIP step therefore has to be chosen carefully to guarantee a good Be layer quality without loosing the mechanical properties of the CuCrZr.

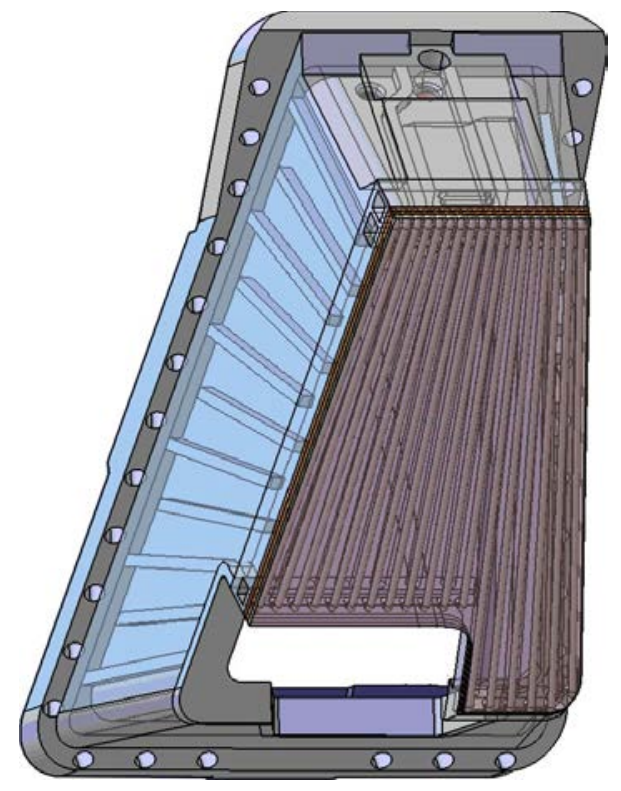

Figure 9. The blanket shield module BSM.

\section{The Launcher Handling and Testing facility}

A prototype testing facility shown in figure 10 has been set up for testing large scale prototypes [20]. It is formed by a water circuit operating up to ITER bake out conditions $\left(240^{\circ} \mathrm{C}\right.$ at 4.4MPa) and a rack for component fixation. Fast heating and cooling ramps allow a wide set of experiments and the examination of basic parameters such as pressure drop or temperature distribution using thermocouples and infrared imaging. The results are used to verify the required component performance [21] as well as to cross check results of fluid dynamic simulations [22]. A standard remote handling arm can be used to simulate maintenance procedures.

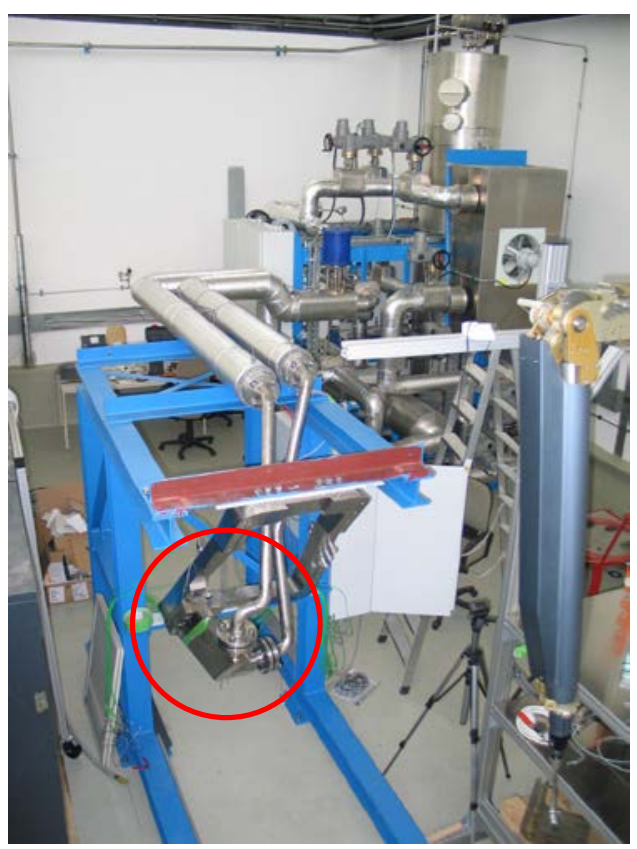

Figure 10. The Launcher Handling and Testing facility LHT.

The prototypes of structural components manufactured up to now are different BSM corner mock-ups (mounted in figure 10) to compare the manufacturing routes of brazing, welding and hot isostatic pressing, first wall panel mock-ups, the BSM flange and an electron beam welded single wall mainframe segment (figure 11, [23]). Experiments continue.

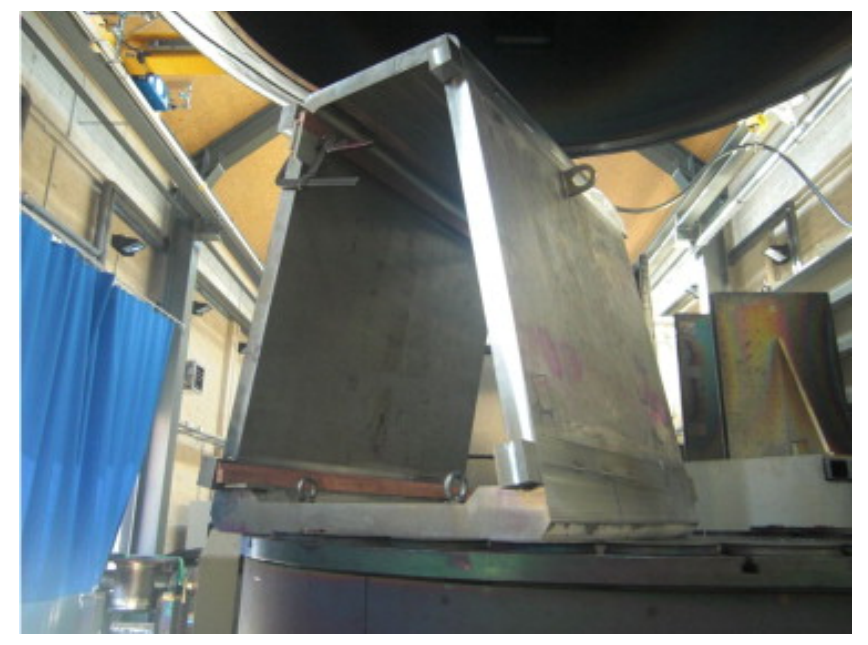

Figure 11. Electron beam welded single wall prototype. 


\section{SUMMARY AND OUTLOOK}

From the conceptual design in 2006 the upper launcher evolved to a preliminary design with improved capabilities for plasma stabilization. Decoupling the upper and lower steering mirrors now allows a wider coverage relieving the equatorial launcher, which now can provide current profile shaping by counter ECCD. The component development is accompanied by prototyping and testing; the manufacturing routes for the critical components are being evaluated. The future work towards the final design will go hand-in-hand with further prototyping and fine tuning of the system.

\section{ACKNOWLEDGMENT}

The authors thank to K. Sakamoto and his team for providing the experimental infrastructure for the long pulse high power testing of the diamond window prototypes at JAEA.

\section{REFERENCES}

[1] M. Henderson and G. Saibene, "Critical interface issues associated with the ITER EC system,” Nuclear Fusion, 48 (2008) 054017.

[2] K. Sakamoto et al, "Steady state operation of 170GHz-1MW gyrotron for ITER,” Nuclear Fusion 48 (2008) 054009

[3] G. Denisov et al, "Dvelopment in Russia of high power gyrotrons for fusion”, Nuclear Fusion 48 (2008) 054007

[4] J.-P. Hogge et al, "First experimental results from the european union 2MW coaxial cavity ITER gyrotron prototype,” Fusion Science and Technology 55 (2009)

[5] Rasmussen D. et al, "Design of the ITER electron heating and current drive waveguide transmission line," Proc. $4^{\text {th }}$ IAEA ECRH Technical Meeting (Vienna, Austria, May 2007)

[6] K. Takahashi et al, "Improved design of an ITER equatorial EC launcher,” Nuclear Fusion 48 (2008) 054014

[7] S. Gunter et al, "High-Confinement Regime at High $\beta_{N}$ Values Due to a Changed Behavior of the Neoclassical Tearing Modes", Phys. Rev. Lett. 87 (2001) 275001

[8] C. Angionia, T.P. Goodman, M.A. Henderson and O. Sauter, "Effects of localized electron heating and current drive on the sawtooth period," Nuclear Fusion 43 (2003) 455
[9] H. Zohm et al, "Comparison of the performance of different options for the ITER ECRH Upper Launcher”, J. Phys.: Conf Ser. 25 (2005) 234

[10] Kobayashi N. et al 2007 "Design of electron cyclotron heating and current drive system of ITER,” Proc. 17th Topical Conf. on RF Power in Plasmas (Clearwater, FL, USA, May 2007)

[11] D. Strauss et al, "Deflections and vibrations of the ITER ECRH upper launcher," Proc. 16th Joint Workshop on Electron Cyclotron Emission and Electron Cyclotron Resonance Heating, Sanya, China, April 12-15, 2010

[12] A. Serikov et al, "Nuclear analyses for the ITER ECRH launcher", Nuclear Fusion, 48 (2008) 054016

[13] R. Heidinger et al, "Conceptual design of the ECH upper launcher system for ITER. Fusion Engineering and Design, 84 (2009)

[14] G. Ramponi et al., "Physics analysis of the ITER ECW system for optimized performance,” Nuclear Fusion, 48 (2008) 054012

[15] M. Henderson et al., "Overview of the ITER ECH upper launcher," Nuclear Fusion 48 (2008) 054013

[16] A. Vaccaro, K. Kleefeldt, K., P. Späh, D. Strauss, "Mechanical analysis of the EC upper launcher with respect to electromagnetic loads," Fusion Engineering and Design, 84 (2009)

[17] Scherer, T.A.et al, "Experimental and theoretical thermal analysis of CVD diamond window units for the ITER upper launcher," Internat.Conf.on Infrared, Millimeter and Terahertz Waves (IRMMWTHz), Pasadena, Calif., September 15-19, 2008

[18] Scherer, T.A.et al, "Recent upgrades of the ITER ECRH CVD torus diamond window design and investigation of dielectric diamond properties," 16th Joint Workshop on Electron Cyclotron Emission and Electron Cyclotron Resonance Heating, Sanya, China, April 12-15, 2010

[19] D. Strauss, G. Müller, G. Schumacher, "Oxide scale growth in MCrAlY coatings after pulsed electron beam treatment," Surface and Coatings Technology, 108-109 (1998)

[20] D. Strauss et al, "Objectives and design of the launcher handling test facility at FZK," US-EU-JPN RF Heating Technology Workshop, Nara, J, September 26-30, 2006

[21] D. Strauss et al, "FEM analyses and prototype tests of the UPP structure for the ECRH in ITER,” Fusion Engineering and Design, 84 (2009)

[22] A. Vaccaro et al, "Fluid dynamics and thermal analysis for the ITER ECH upper launcher", Proc 5th IAEA Techn. Meeting on ECRH Physics and Technology for Large Fusion Devices, Gandhinagar, India, (2009)

[23] P. Spaeh et al, "Manufacturing studies of structural components for the ITER EC upper launcher,” Fusion Engineering and Design, 85 (2010) 